\section{EREM 75/4}

Journal of Environmental Research, Engineering and Management

Vol. 75 / No. 4 / 2019

pp. 18-29

DOI 10.5755/j01.erem.75.4.23072
Techno-economic Analysis of the Olive Oil Mills Waste Valorisation for Energy Production: A Case Study of Corfu

Received 2019/04

Accepted after revision 2019/12

\title{
Techno-economic Analysis of the Olive Oil Mills Waste Valorisation for Energy Production: A Case Study of Corfu
}

\section{Anastasios Tasionas}

School of Science and Technology, Hellenic Open University (HOU), GR-26222, Patras, Greece

\author{
Athanasios Sotirios Dounavis* \\ University of Western Macedonia, UOWM, Koila, GR-50100, Kozani, Greece \\ School of Science and Technology, Hellenic Open University (HOU), GR-26222, Patras, Greece
}

\section{*Corresponding author: adounavis@uowm.gr}

Olive oil production in Greece is undoubtedly linked to its history and tradition. However, large quantities of by-products that are harmful to the environment are produced (with the olive oil production). Those environmental problems are a result of the chemical composition of the waste and its high organic load. On the other hand, this kind of biomass holds an extremely high energy potential, if treated correctly. This intense phenomenon has led to the exploration and development of methods and technologies for the treatment of olive mill waste. One of the methods used is biogas production through anaerobic digestion and its subsequent disposal for energy production. This method could be particularly appealing to the Greek islands, as they depend for energy on mainland Greece, or are powered by diesel power plants. A typical example is the island of Corfu where the problem of waste from olive oil mills is intense and its energy demands are increased due to the growth of the tourism industry. Therefore, energy production via anaerobic digestion could greatly contribute to overcoming the current situation. The purpose of this study is to examine the feasibility of an electricity production plant on the island of Corfu, which is fed by biogas, taking into account the high amount of olive oil mill waste produced in this area.

Keywords: anaerobic digestion, Corfu, waste management, olive oil mills, biogas, heat, electricity.

\section{Introduction}

The Regional Prefecture of Corfu is the second largest Unity of the lonian Islands region and includes the islands of Corfu, Paxos, Antipaxos and the small islands of Othoni, Erikousa and Mathraki. Its total area is $641 \mathrm{~km}^{2}$, with the majority of the prefectures being classified as rural (91\%), while the lowlands cover $72 \%$ of the Regional Unity.

In Greece, the olive tree is grown in 50 regions of the country and it is estimated by the Greek Statistical Service (GSS, 2019) that there are around 150 million olive trees, 2,500 mills and 80 olive-oil processing 
factories. The Peloponnese (29.1\%) followed by Crete (27.3\%) and the Region of Western Greece (20\%) have the largest percentage of cultivated land.

The number of olive trees cultivated in the Peripheral Unity of Corfu is estimated to be $1,999,648$, which corresponds to $1 \%$ of the total olive trees in Greece. The olive oil production amounts to almost 12,000 tons per year, which corresponds to 3.3\% of the total Greek production. In the region, there are 98 active olive oil mills, of which only 2 are two-phase and the rest are three-phase. It is noteworthy that, according to the requirements of the European Union, all olive oil mills must be twophase mills (Stamatakis, 2010).

According to the data from the Department of Agriculture of Corfu, the Greek Statistical Service and the Region Authorities of Corfu, the average processed olive oil for the years 2013-2017 (divided into four olive years) is $43,094,301.44 \mathrm{~kg}$ per year and the average olive oil production is $8,460,747.2 \mathrm{~kg}$ per year (GSS, 2019). At this point, it is necessary to point that only 33 mills of 98 provide data to the Agriculture Directorate.

Figure 1 shows their distribution in the region. The mills are not evenly distributed in the island, but are concentrated in the southern and northern parts, while in the middle of the island there are very few. This is expected, as businesses gather around the olive groves grown in the northern and southern regions of the island. Striking is the fact that more than two olive presses are concentrated in a very small area, mainly in the northern regions, which shows the fragmentation of production without a centralized management of the olive oil industry.

The basic process for the olive oil production is the extraction through pressing, which is the traditional way. Nowadays, the extraction is performed with the centrifugal process through three-phase or two-phase decanters. Extraction through three-phase decanters produces a stream of olive oil mixed with water for further centrifugation, a stream of wastewater (katsigaros) and
Fig. 1.Spatial structure of olive presses in Corfu (image from Google Earth).

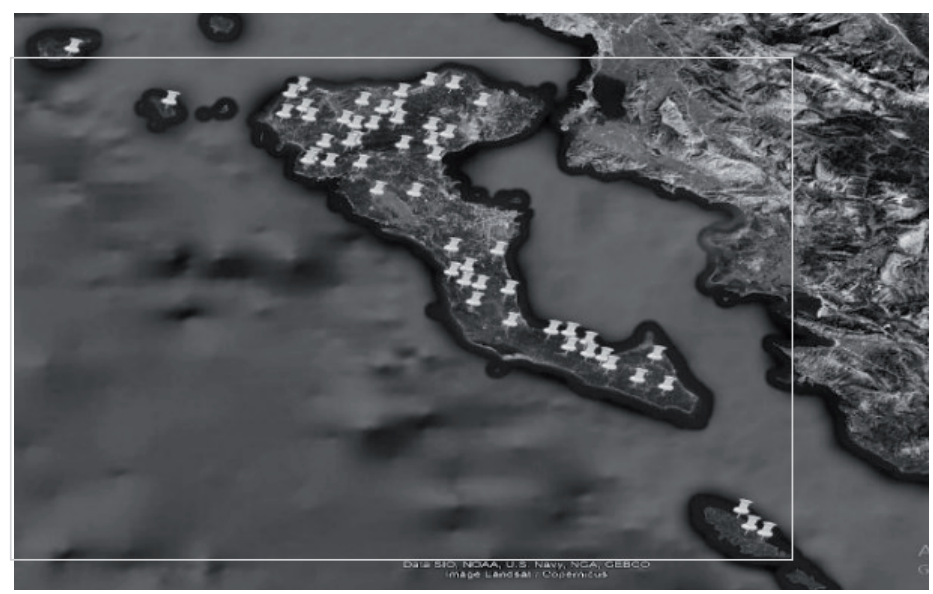

solid waste (pomace or trifasikos elaiopirinas) (Fountoulakis et al., 2002). Extraction through two-phase decanters produces a stream of olive oil for further centrifugation and solid waste (Valta et al., 2015). Figure 2 shows the flow diagram of the three olive oil extraction processes.

Fig. 2. Flow diagram of the three olive oil extraction processes: (A) traditional method, (B) three-phase extraction process, $(C)$ two-phase extraction process (Kalderis \& Diamadopoulos, 2010).

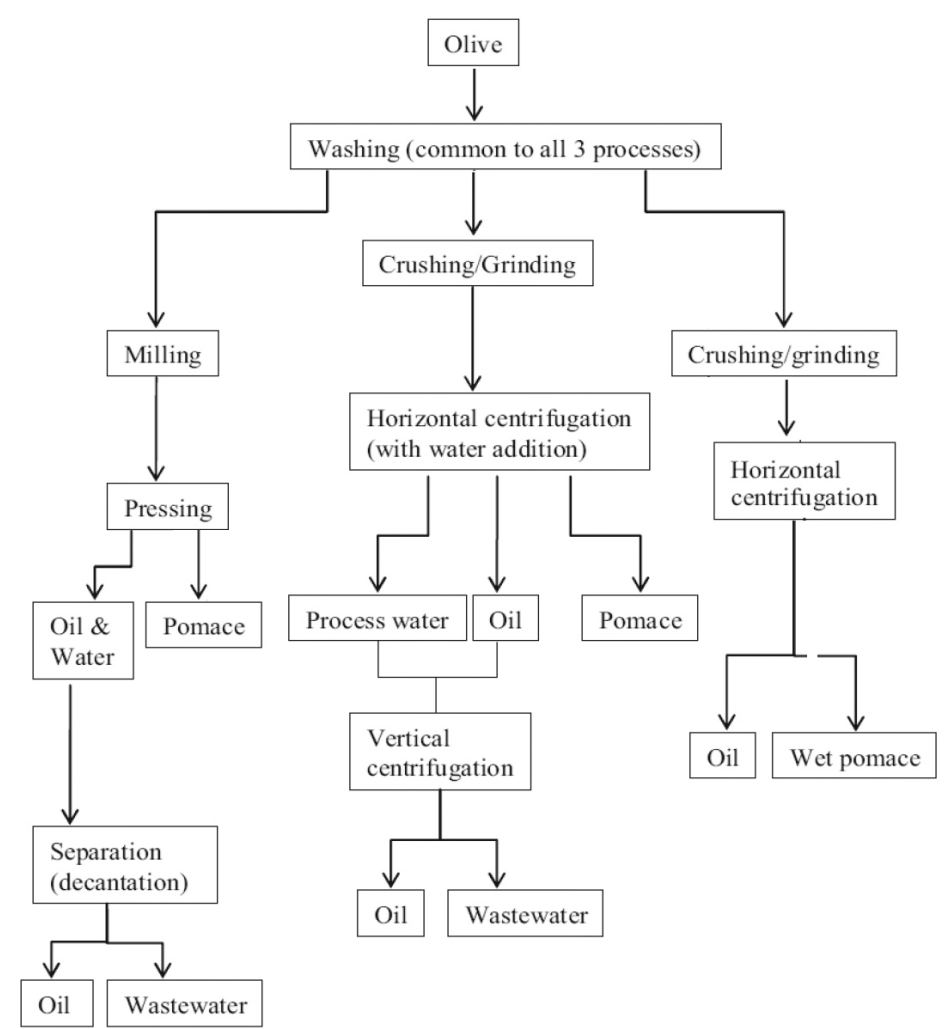


The handling and processing of olive oil waste are the main environmental problems of the Mediterranean area (Loumou \& Giourga, 2003), which is a challenge for all countries producing olive oil. Due to the nature of the waste, its disposal becomes easily uncontrolled (Kavvadias et al., 2010). Supposing there is an increasing trend in demand for olive oil, it is obvious that this problem is even bigger (Morillo et al., 2009).

In order to understand the problem more easily, the chemical composition of the olive should be studied, which is not stable and depends on its variety, soil type, climatic conditions and many other factors. Its general composition is $18-28 \%$ of oil, $40-50 \%$ of vegetable water and pomegranate and $30-35 \%$ of olive pulp (Morillo et al., 2009; Hall, 1992). This composition, in combination with the mechanical processes of olive oil production, produces large amounts of liquid and solid waste, which are characterized by a high organic load. The quantity of liquid waste amounts to $0.5-1.5 \mathrm{~m}^{3}$ per 1,000 $\mathrm{kg}$ of olives, which depends on the type of production process. In general, the traditional process produces less but more concentrated waste $\left(0.5-1 \mathrm{~m}^{3}\right.$ per 1,000 $\mathrm{kg}$ ) from the centrifugation process $\left(1-1.5 \mathrm{~m}^{3}\right.$ per 1,000 kg) (Paraskeva \& Diamadopoulos, 2006).

Olive oil industry wastes have a characteristic dark colour due to high concentrations in lignites and tannins and generally resistant compounds, but the most serious and dangerous problem, from an environmental view, is their content of fatty acids and long-chain phenolic compounds. These compounds cause a problem in microorganisms and plants as they are particularly toxic, while altering the biological balance of the soil, leading to reduced fertility and phytotoxicity (Paraskeva $\&$ Diamadopoulos, 2006). At the same time, they convey dangerous substances to the liquid recipients, resulting in groundwater-surface pollution and algae growth due to eutrophication.

Regarding pomace, there are two ways to manage the mills in Corfu. The first and most common is their temporary storage and their subsequent transport and resale (like in Skripero area). The second is depositing and drying them in fields and then selling them as fuel or burning them in boilers for heating the olive oil.

The largest environmental problem in Corfu is caused by wastewater (katsigaros). The operating conditions of most olive mills indicate that each company is required to dispose of the liquid waste in properly designed evaporator tanks or to pre-treat it with lime before disposal. Although most mills have lagoons, the large olive oil production exceeds the capacity of the plant, resulting in excess waste reaching streams and from there to the sea. Figure 3 illustrates the situation in December 2009 on the beach of Agios Georgios Pagon area, following an uncontrolled disposal of liquid waste from the oil mills. This situation continues to date, with most mills unable to manage the problem, except for some companies which have reduced the olive oil production (with increased quality) and completely manage their waste. Nowadays, in Corfu, an effort is made by the local olive oil liaison to ensure the complete management of their wastewater through the development of a composting plant.

Fig. 3. Panoramic view of Agios Georgios Pagon beach in December 2009 (web source).

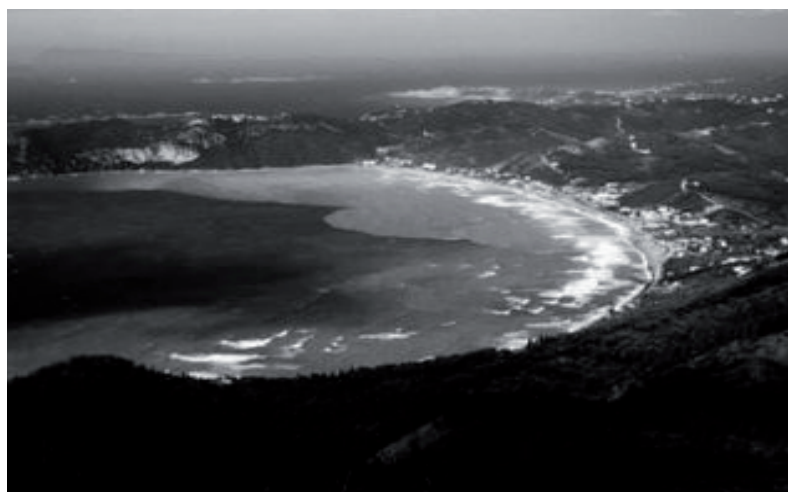

Energy source production by anaerobic decomposition of organic waste is the most important benefit for the biogas technology. During the anaerobic digestion process, the organic matter decomposes into methane $\left(\mathrm{CH}_{4}\right)$ and carbon dioxide $\left(\mathrm{CO}_{2}\right)$. The process takes place in the absence of oxygen and with the simultaneous action of microorganisms. It is a biological process with excellent results to wastewater treatment. Its advantage comes from the achievement of energy savings as well as from the fact that a low sludge content is produced in the treatment of high COD wastewater (Blika et al., 2009; Komnitsas et al., 2012). Biogas production in rural areas can have several advantages, such as the release of its electricity, coal, fuel oil, wood for heating and avoiding problems with the administration and distribution network. Organic matters for biogas production are easily accessible and reduce the use of firewood and preserve forest. 
Although there are three anaerobic processes (methanogenic anaerobic digestion (methane), biological hydrogen production (hydrogen) (Dounavis et al., 2015) and microbial fuel cell technology (electricity)), anaerobic digestion is one of the technologies used to produce energy as well as to stabilize the waste. Furthermore, anaerobic digestion is already successfully used for many agro-industrial residues, such as sugar beet pulp, potato pulp, potato thick stillage or brewers' grains. This technology allows an efficient solids stabilization and energy recovery, while both wastes from two-phase and three-phase extraction processes are shown to be promising substrates for anaerobic digestion (Rincón et al., 2012; Ošlaj \& Muršec, 2010). For all

\section{Methodology}

In order to achieve the desired goal of designing a power plant for anaerobic digestion of olive oil mill waste, four steps are necessary. The first step was to estimate the amount of solid waste and water waste, which are currently produced in Corfu. So far, there is no evidence of quantitative and qualitative waste olive oil production from Corfu and, therefore, the quantity was estimated, based on olive oil production data from the Department of Agriculture of Corfu for the last four years and the visit to olive oil mills. This data was combined with international literature data the above reasons, this technology is attractive for the case of Corfu.

There are a number of studies regarding the process of anaerobic digestion of olive press waste, which analyze the full range of process parameters and produce results for the quantity and quality of the produced biogas. These studies investigate different practices of anaerobic digestion (La Cara et al., 2012; Montero et al., 2011; Bauer et al., 2013) and end up in the equipment of the centralized unit (Sutton, 1990; Samer, 2012; Ahmad, 2004). However, there is no mention of the economic results from the operation of a commercial biogas plant. Also, there is no study to build such a unit in an island, considering the peculiarities of the location.

(Montero et al., 2011; Fabien, 2003), and the estimated quantities of olive oil waste were obtained. The next step for sizing was to estimate biogas production if all the quantities of waste were treated anaerobically. The evaluation was again based on international bibliography (Dounavis et al., 2016; Koutrouli et al., 2009). The sizing of plant and machinery was done by searching and retrieving information from websites of companies, specializing in the equipping of these facilities. The last step concerned the required funds and the financial gain which would result from this

Fig. 4. Methodology of designing a power plant for anaerobic digestion of olive oil mill waste in Corfu.

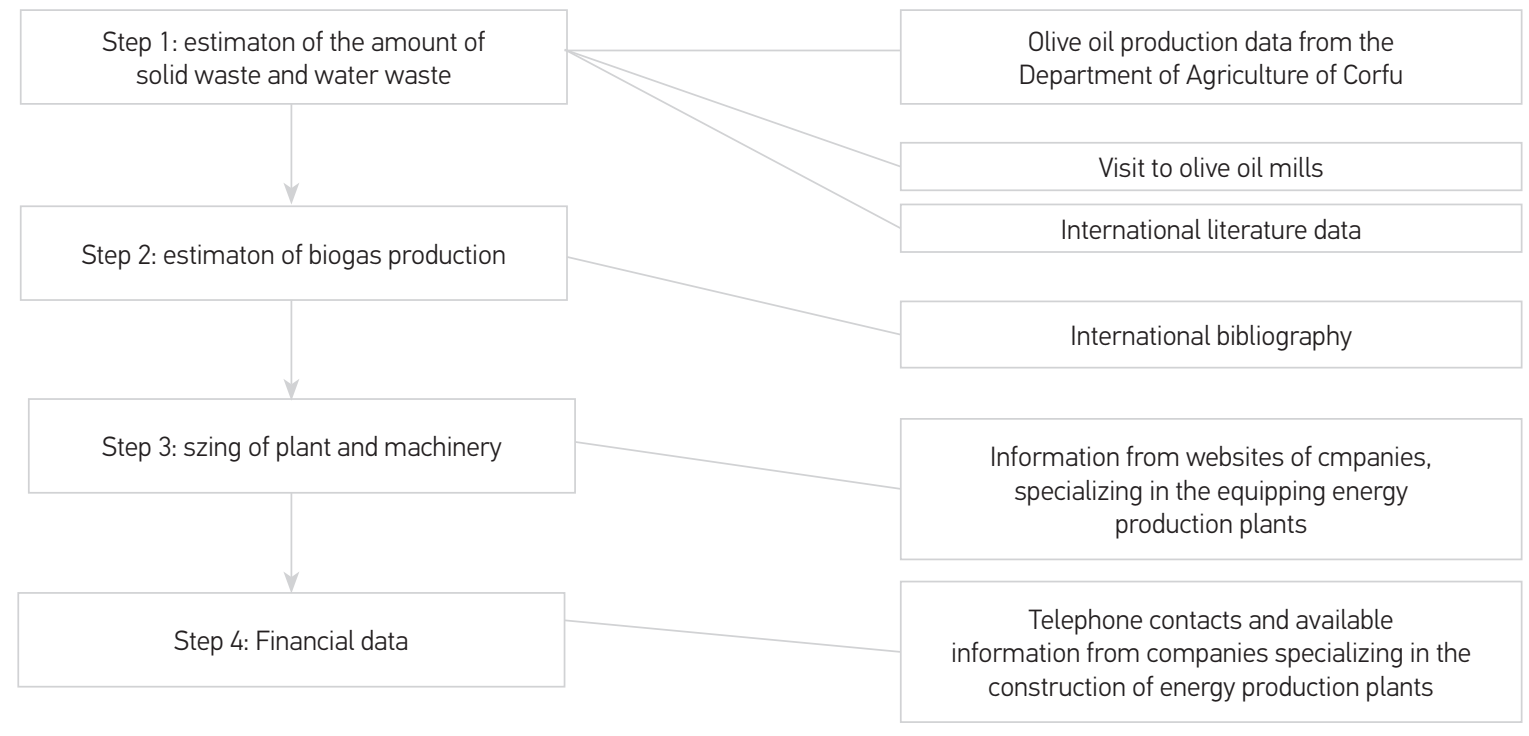


unit. As there is insufficient evidence in the international literature on the required financial figures for the construction of a power plant, their assessment was based on the data gathered through telephone contacts and through available information from companies specializing in the construction of these projects. The financial data was calculated related to the initial investment cost of the unit, the cost of its operation and the profit which would be generated by the distribution of electricity. For this purpose, three

\section{Results and Discussion}

\section{Calculation of Energy Consumption and Production}

According to the data retrieved from the Department of Agriculture of Corfu and the National Statistical Service, the average olive oil processed for the years 2013-2017 (divided into four olive years) is $43,094,301.44 \mathrm{~kg} /$ year and the average olive oil production is $8,460,747.2 \mathrm{~kg} /$ year. The unit's dimensioning was calculated based on the production of 33 olive mills as these are the only mills that give data to the Department of Agriculture. The actual oil production is larger but there is a difficulty in estimating it as many mills do not work throughout all the olive-growing periods or only operate for a few months. As there are no data on the quantity of solid and liquid waste, it is necessary to make an estimate of these quantities based on the literature. Thus, according to this, from about $1,000 \mathrm{~kg}$ of olives, about $500 \mathrm{~kg}$ of solid waste is produced, which contains about $3 \%$ of olive oil, $50 \%$ of moisture and 1,200 L of liquid waste. Table 1 shows the capacity of olive presses in Corfu and the estimate of waste generation for the years 2013-2017.

The average solid waste generation is $20,246.855$ tons scenarios were investigated: a) construction without subsidy and free distribution of soil improver, b) construction without subsidy and sale of soil improver for $40 € /$ ton, and c) construction with $40 \%$ subsidy and sale of soil improver for $40 € /$ ton. Figure 4 illustrates the developed methodology. Simultaneously, the social and political conditions required were examined for the development of a power plant in Corfu, as well as the Greek legislative framework governing the operation and especially the construction.

per year and the wastewater production is $51,713,161$ $\mathrm{m}^{3} /$ year. Taken into consideration that the waste density is $1,022 \mathrm{~kg} / \mathrm{m}^{3}$, the estimated wastewater production is $52,850.50$ tons per year on average. As the amount of biogas produced from $1 \mathrm{~kg}$ of waste is 0.5 $\mathrm{m}^{3}$ and $1 \mathrm{~m}^{3}$ of liquid waste is $6 \mathrm{~m}^{3}$, the anaerobic digestion of solids will result in 10,123,428 $\mathrm{m}^{3} /$ year of gas, while the digestion of fluids will result in 310,279 $\mathrm{m}^{3} /$ year of gas. The mills operate mainly throughout the period (oil production) from the end of October (beginning of November) until mid-March, which is about 4.5 months a year. The amount of waste which the unit will receive (for 135 full days), will be $149,977 \mathrm{~kg}$ of solid waste per day and $383 \mathrm{~m}^{3}$ of liquid waste per day. In order to be attractive to invest in a power plant, it is necessary to operate for at least 11 months a year (which corresponds to about 330 days a year), as the $12^{\text {th }}$ month is considered a month of maintenance work. This means that it is necessary to provide storage of olive oil. Although this is easy regarding solid waste, this is not the case with the liquid waste, which is necessary to process within 1-2 days from the moment the unit will receive it.

Table 1. Capacity of Corfu mills and waste production estimate for the years 2013-2017, according to the data of the Directorate for Agriculture of Corfu, the National Statistical Service and the Region of Corfu

\begin{tabular}{c|c|c|c|c}
\hline OLIVE SEASON & $\begin{array}{c}\text { OLIVE FRUIT } \\
\text { PRODUCTION IN kg }\end{array}$ & $\begin{array}{c}\text { OLIVE OIL } \\
\text { PRODUCTION IN kg }\end{array}$ & $\begin{array}{c}\text { SOLID WASTE } \\
\text { PRODUCTION IN kg }\end{array}$ & $\begin{array}{c}\text { LIQUID WASTE } \\
\text { PRODUCTION IN L }\end{array}$ \\
\hline $2013-2014$ & $43,324,700$ & $8,748,967$ & $20,355,103$ & $51,989,640$ \\
\hline $2014-2015$ & $59,428,697$ & $12,001,000$ & $27,921,192$ & $71,314,436$ \\
\hline $2015-2016$ & No data available & No data available & No data available & No data available \\
\hline $2016-2017$ & $26,529,507$ & $4,632,274$ & $12,464,272$ & $31,835,409$ \\
\hline Average & $\mathbf{4 3 , 0 9 4 , 3 0 1 . 4 4}$ & $\mathbf{8 , 4 6 0 , 7 4 7 . 2}$ & $\mathbf{2 0 , 2 4 6 , 8 5 5 . 9}$ & $\mathbf{5 1 , 7 1 3 , 1 6 1 . 7 3}$ \\
\hline
\end{tabular}


The maximum production from olive oil mills is during the months of November-February, and so the plant will reach its maximum capacity in four months.

Based on the above data and given that the calorific value of the biogas is $6.5 \mathrm{kWh} / \mathrm{m}^{3}$ and the fact that the unit will be fed with solid waste for 11 months per year while with solids and fluids for 4.5 months, the energy production is given in Table 2 .

Table 2. Elements of capacity of the anaerobic digester of olive mill waste in the EU Corfu

\begin{tabular}{c|c|c|c|c|c} 
& Months per year & Solid waste $(\mathrm{t} / \mathrm{h})$ & Wastewater $(\mathrm{m} 3 / \mathrm{h})$ & Biogas $(\mathrm{m} 3 / \mathrm{h})$ & Energy production MW \\
\hline Solid waste supply & 6.5 & 2.56 & - & 1,112 & 7.23 \\
\hline $\begin{array}{c}\text { Solid and wastewater } \\
\text { supply }\end{array}$ & 4.5 & 2.56 & 15.96 & 1,208 & 7.85 \\
\hline
\end{tabular}

Table 3. Requirements for mechanical equipment in electricity of the anaerobic power plant for the wastewater treatment of oil mills in Corfu

\begin{tabular}{l|c|c}
\multicolumn{1}{c|}{ Electromechanical equipment } & Power consumption in kW & Operating period (months) \\
\hline Crushing machine & 11 & 4.5 \\
\hline Homogeneous wastewater mixer & 11 & 11 \\
\hline Transporter tube engine & 1 & 4.5 \\
\hline Waste water pump & 1 & 4.5 \\
\hline Dilution water pump & 11 & 11 \\
\hline Solid waste digester mixer & 15 & 4.5 \\
\hline Liquid waste digester mixer & 132 & 11 \\
\hline Biogas compressor of vapour removal unit & 132 & 11 \\
\hline Biogas sewer unit compressor & 242 & 11 \\
\hline PSA unit (CO2 removal) & 529 & 11 \\
\hline Simple feeding set & 534 & $\mathbf{4 . 5}$ \\
\hline Double feeding set & 11 & 11 \\
\hline
\end{tabular}

Table 4. Thermal energy requirements of the anaerobic power plant of an oil mill in the EE Corf

\begin{tabular}{l|c|c}
\hline \multicolumn{1}{c|}{ Operation } & Thermal energy consumption in $\mathrm{kW}$ & Operating period (months) \\
\hline Preheating of liquid waste & 564.2 & 4.5 \\
\hline Preheating of solid waste & 17.3 & 11 \\
\hline Wastewater digester heating & 16.3 & 11 \\
\hline Solid waste digester heating & 5.6 & 11 \\
\hline Heat absorber cooler & 77.1 & 11 \\
\hline Vapour removal heating & 26.6 & 11 \\
\hline Simple feeding set & 126.6 & $\mathbf{4 . 5}$
\end{tabular}


Table 5. Thermal energy requirements of the anaerobic power plant of an oil mill in the EE Corf

\begin{tabular}{l|c|c|c|c|c|c|}
\hline & $\begin{array}{c}\text { Electricity } \\
\text { production } \\
\text { in } \mathrm{kW}\end{array}$ & $\begin{array}{c}\text { Power } \\
\text { consumption } \\
\text { in } \mathrm{kW}\end{array}$ & $\begin{array}{c}\text { Thermal energy } \\
\text { production } \\
\text { in } \mathrm{kW}\end{array}$ & $\begin{array}{c}\text { Consumption of } \\
\text { thermal energy } \\
\text { in } \mathrm{kW}\end{array}$ & $\begin{array}{c}\text { Net electricity } \\
\text { production } \\
\text { in } \mathrm{kW}\end{array}$ & $\begin{array}{c}\text { Net thermal } \\
\text { energy } \\
\text { production } \\
\text { in } \mathrm{kW}\end{array}$ \\
\hline Simple feeding & 2,950 & 529 & 2,832 & 127 & $\mathbf{2 , 4 2 2}$ & $\mathbf{2 , 7 0 6}$ \\
\hline Double feeding & 3,204 & 534 & 3,076 & 684 & $\mathbf{2 , 6 7 0}$ & $\mathbf{2 , 3 9 2}$ \\
\hline
\end{tabular}

After the dimensioning of the mechanical equipment, in Tables 3 and 4, the required electrical and thermal energy for the operation is presented.

Finally, in Table 5, the total production and consumption of electrical and thermal energy are presented as well as the final electricity and thermal energy remaining for exploitation after the needs of the unit.

To make a comparison with a similar plant that is already in operation, the best reference is an anaerobic waste treatment plant which is already operating on the island of Lesvos, but which has two major differences. The first difference is that the island of Lesvos plant processes all types of organic waste (not only olive oil waste) and the second one is that it works with a specific rated power of $500 \mathrm{~kW}$. This unit, according to the environmental impact study, generates 3,599 MWhe per year of pure electricity from 24,750 tons of waste per year. Assuming that the Corfu unit will work for the same amount of time (7,920 hours/ year) and it will process the same amount of waste per year, (but only olive oil waste) then, the net electric energy produced by the plant would be 6,810 MWhe per year (Ministry of Environment and Energy, 2019), which is almost double the energy of Lesvos unit. This indicates the high energy value of the olive oil mills waste and the capabilities of Corfu in order to produce its own energy.

Financial Data. The financial data to be calculated relates to the initial investment cost, its operating costs and the profit which will be generated by the distribution of electricity.

Initial investment costs, as well as operating costs, are directly related to the applied technology as well as the mechanical equipment. In general, the cost of operation and maintenance of pre-treatment systems is lower as much as the organic waste entering the unit is cleaner. Moreover, the more cost of manufacturing increases, the more technologically advanced is the selected technology (bioreactors selection). Conversely, the cost of construction and operation is reduced per ton of waste as the capacity of the unit increases.

Based on the literature, an anaerobic digestion unit of the estimated size (70,000 tons of waste per year) has a service life of 20 years and an initial investment cost of 2,800 $€ /$ ton of incoming waste (Eunomia Research $\&$ Consulting Ltd, 2009). In the case of Corfu, the initial investment cost will be around 19,600,000 €. It should be noted that this amount has not taken into account the cost of acquiring the land in which the investment will be made. The unit's operating costs include the current tax legislation, energy requirements, sewage management, maintenance of electromechanical equipment and labour cost.

Based on the literature (Eunomia Research \& Consulting Ltd, 2009), this kind of electricity production plants has an operating cost of $20 € /$ ton of waste per year, so the annual operating cost will be around $€ 1,400,000$.

The following assumptions are used to calculate the profit that will be generated by the unit's operation:

The energy sizes calculated in the above sections refer to maximum unit operation (maximum load);

The average maximum power output of the unit is $2.5 \mathrm{MW}$;

The average maximum heat output of the unit is $2.5 \mathrm{MW}$;

The total annual heat supply to the grid is $12,500 \mathrm{MWh}$; 
The cost of transporting the waste to the plant will be borne by each mill;

The selling price of MWh is $€ 175$ (readjustment of the tariffs of article 5 of Law 3851/2010);

Annual energy consumption per household is 3,500 kWh per household. With the view of the 3 inhabitants per household and the total number of 101,113 inhabitants, the annual energy needs of the Corfu Regional Unit amount to 88.47 GWh.

According to the above assumptions, the total annual profit from the sale of electricity and thermal energy amounts to $€ 3,000,000$ per year. The net annual profit of the plant (if the operating cost is deducted and provided that the soil improver is free of charge) will be $€$ $1,600,000$, while the total depreciation time of the initial cost is 7 years and the total electricity produced is $14.13 \%$ of the total energy demand of the Corfu Regional Unity.

If the same scenario is studied but provided that the soil improver is sold at its commercial value (40 €/ ton), then the depreciation time is reduced to 6 years. Lastly, it is necessary to mention that the cost of constructing for this investment is not entirely borne by the private investor, due to the fact that in recent years, investments in renewable energy sources have been made through public-private sector partnerships. These partnerships are carried out with a partial subsidy from the European Union and are under the management of the private investor for a long time. At the end of that period, the ownership is transferred to the State.

Taking into account this scenario and assuming that the construction is subsidized at $40 \%$ of the investment cost, as well as the sale of the soil improver is $40 € /$ ton, then the total depreciation time of the initial cost is reduced to 3 years.

In Tables 6, 7, and 8, the financial data for the three (3) scenarios are presented.

Table 6. Economic data of the anaerobic digester of olive mill waste for Corfu (scenario 1: no subsidy - soil improver free of charge)

\begin{tabular}{|c|c|}
\hline \multicolumn{2}{|c|}{ Financial data of the first scenario } \\
\hline Citizens & 101.113 \\
\hline Electricity per year per household in MWh & 3.5 \\
\hline Citizens per household & 4 \\
\hline Energy requirement per year in MWh & 88.474 \\
\hline Mean maximum output of electric and thermal energy in MW & 5 \\
\hline Operating hours per year & 5.000 \\
\hline Provision of electricity and heat to the grid per year in MWh & 25.000 \\
\hline Electrical network coverage & $14.13 \%$ \\
\hline MWh in $€$ & 175 \\
\hline Annual profit in $€$ & 4.375 .000 \\
\hline Annual operating cost in $€$ & 1.400 .000 \\
\hline Net annual profit in $€$ & 2.975 .000 \\
\hline Investment cost in $€$ & 19.600 .000 \\
\hline Depreciation of investment in years & 7 \\
\hline
\end{tabular}


Table 7. Economic data of the anaerobic digester for olive oil waste for Corfu (scenario 2: no subsidy - sale of soil improver for $40 € / t$ )

\begin{tabular}{|c|c|}
\hline \multicolumn{2}{|c|}{ Financial data of the second scenario } \\
\hline Citizens & 101.113 \\
\hline $\begin{array}{l}\text { Electricity per year per } \\
\text { household in MWh }\end{array}$ & 3.5 \\
\hline Citizens per household & 4 \\
\hline $\begin{array}{l}\text { Energy requirement per year in } \\
\text { MWh }\end{array}$ & 88.474 \\
\hline $\begin{array}{l}\text { Mean maximum output of electric } \\
\text { and thermal energy in } \mathrm{MW}\end{array}$ & 5 \\
\hline Operating hours per year & 5.000 \\
\hline $\begin{array}{l}\text { Provision of electricity and heat to } \\
\text { the grid per year in MWh }\end{array}$ & 25.000 \\
\hline $\begin{array}{l}\text { Electrical network } \\
\text { coverage }\end{array}$ & $14,13 \%$ \\
\hline MWh in $€$ & 175 \\
\hline $\begin{array}{l}\text { Annual profit from the } \\
\text { sale of soil improver in } €\end{array}$ & 404.735 \\
\hline Annual profit in $€$ & 4.779 .735 \\
\hline Annual operating cost in $€$ & 1.400 .000 \\
\hline Net annual profit in $€$ & 3.379 .735 \\
\hline Investment cost in $€$ & 19.600 .000 \\
\hline $\begin{array}{l}\text { Depreciation of investment in } \\
\text { years }\end{array}$ & 6 \\
\hline
\end{tabular}

Table 8. Economic data of the anaerobic digester for olive oil waste for Corfu (scenario 3: 40\% subsidy - sale of soil improver for $40 € / t$ )

\begin{tabular}{|c|c|}
\hline \multicolumn{2}{|c|}{ Financial Data of the third scenario } \\
\hline Citizens & 101.113 \\
\hline $\begin{array}{l}\text { Electricity per year per } \\
\text { household in MWh }\end{array}$ & 3.5 \\
\hline Citizens per household & 4 \\
\hline $\begin{array}{l}\text { Energy requirement per year } \\
\text { in } \mathrm{MWh}\end{array}$ & 88.474 \\
\hline $\begin{array}{l}\text { Mean maximum output of } \\
\text { electric and thermal energy in } \\
\text { MW }\end{array}$ & 5 \\
\hline Operating hours per year & 5.000 \\
\hline $\begin{array}{l}\text { Provision of electricity } \\
\text { and heat to the grid per } \\
\text { year in MWh }\end{array}$ & 25.000 \\
\hline $\begin{array}{l}\text { Electrical network } \\
\text { coverage }\end{array}$ & $14.13 \%$ \\
\hline MWh in $€$ & 175 \\
\hline $\begin{array}{l}\text { Annual profit from the sale of } \\
\text { soil improver in } €\end{array}$ & 404.735 \\
\hline Annual profit in $€$ & 4.779 .735 \\
\hline Annual operating cost in $€$ & 1.400 .000 \\
\hline Net annual profit in $€$ & 3.379 .735 \\
\hline Investment cost in $€$ & 19.600 .000 \\
\hline Subsidy 40\% & 7.840 .000 \\
\hline $\begin{array}{l}\text { Depreciation of investment in } \\
\text { years }\end{array}$ & 3 \\
\hline
\end{tabular}




\section{Conclusions}

The solid waste from the 98 oil mills of the island will end up in the plant and after passing from the storage phase (so that there is a steady flow in the digesters), they will be led to the pre-treatment stage (crumbling) and then to the digester. Biogas production is estimated at $1,208 \mathrm{~m}^{3} / \mathrm{h}$, which will ultimately deliver about 2.4 MW of electricity and $2.7 \mathrm{MW}$ of thermal. At this point, it should be stressed that if the wastewater treatment plant is also treated at this plant (4.5 months), the electricity production reaches at $2.6 \mathrm{MW}$ and the thermal is at $2.4 \mathrm{MW}$. Due to the high power output, the unit is required by law to be connected to the medium voltage network, which adds another obstacle to the choice of the appropriate installation site. It is worth mentioning that the island of Corfu has requirements for electricity consumption of $200 \mathrm{MW}$ in peak periods (summer months) and $100 \mathrm{MW}$ for periods of low demand (winter months). Therefore, the amount from both electricity and thermal production (at 2.4 and $2.6 \mathrm{MW}$, respectively) seems to be very significant, taking into consideration that a little island (like Mathraki or Othonoi) has a maximum demand of $1.5 \mathrm{MW}$. The benefits of implementing a biogas plant from anaerobic digestion of oil mill waste has no impact only on olive growers but on the whole of Corfu's society. As far as the investment is concerned, the following is important:

It covers the energy and thermal needs of olive growers.

It contributes to the island's energy balance as the island's energy dependence on fossil fuels and the transport of electricity from mainland Greece is reduced.

Reducing greenhouse gas emissions by avoiding the production of electricity from diesel engines. The carbon dioxide produced during the operation of the generator is completely renewable unlike that produced by a diesel generator. Suggesting that the island of Corfu is powered by a diesel power plant, then the carbon dioxide emitted by the generator does not constitute additional carbon production and at the same time reduces the amount of diesel consumed by the power plant that feeds the island with electricity.
The annual amount of diesel saved is calculated as follows; the burning of one litre of diesel produces 2,778 $\mathrm{g} \mathrm{CO}_{2}$ and it is estimated that the total energy value of the biogas produced, by the Corfu unit, is $57,261,699$ kWh per year. This corresponds to avoiding burning $5,726,169.9$ litres of diesel per year. That is to say, the operation of the project will reduce $\mathrm{CO}_{2}$ emissions by 15.909 tons per year (Ministry of Environment and Energy, 2019).

A total amount of 20,000 tons of solid waste per year and $52,850.50$ tons per year of liquid waste would be led for treatment energy production, leaving the sea, waters and soil of the island intact and clean.

It improves the environment as there is integrated management of solid and liquid waste from olive-oil mills.

It creates new jobs.

It will improve the environmental image and consequently the social acceptance of using environmentally friendly technologies.

On the other hand, there are several obstacles to overcome to make this investment work:

It is based on seasonal olive oil production which fluctuates greatly each year, so the flow of waste in the plant is not steady.

Although its principle of operation is simple, the overall installation and mechanical equipment is complex, with high initial investment, big maintenance cost and it needs specialized staff.

The transporting of the waste to the plant is very costly.

The reactions of the inhabitants from the surrounding area are taken for granted.

The olive mill owners are treating the pomace as fuel (and not as waste).

For the calculation of the investment, data on the operation of the 98 olive oil mills are necessary. The official data available for Corfu (for example, the 2016-2017 olive oil period) show the operation of $1 / 3$ of them, with no data on the operation of the rest. 
The last three obstacles are also critical to the decision to implement because there should be the certainty that the plant will operate seamlessly and without interruption in order to finance the installation. Furthermore, there must be assurance that all solid waste will end up in the plant.

As anaerobic digestion is more effective than other biological waste treatment methods, the cost of a centralized olive mill processing plant could be quickly depreciated. In order to overcome the seasonal habit, it could also be possible to feed other types of waste, such as waste from local dairies, butchers, but mainly from the organic part of urban waste. The main benefit of this upgrading would be the "relieve" of the local landfill site, which is currently saturated and cannot accept additional urban waste.

Moreover, in order to reduce the cost of transporting olive oil waste from the olive presses operating in the southern region of the island, a second unit could be constructed in the south part of the island, and in particular near the new landfill site of Lefkimmi, which has been built and planned to operate in the future. An improvement of this solution would be the cooperation of nearby olive mills (5-6 in number) with the creation of an equal number of digestion units.

In order to overcome the obstacles to the reactions, in principle it is necessary to involve local authorities in the information and the necessity of involving the local community in this investment. Leaders in this would be oil producers and olive mill owners. It is necessary to establish a co-operative body, which will not only control the production and distribution of olive oil but also it will have an active role in the management of waste. There should be a central control of all olive growers and mills in terms of the waste produced and their management so that the waste stream to the plant is

\section{References}

Ahmad N. (2004) Generation of Biogas from Olive Mill Waste. World Renewable Energy Congress VIII (WREC 2004). Denver, USA.

Bauer F., Christian H., Tobias P. and Daniel T. (2013) Biogas upgrading - Review of commercial technologies. SGC Rapport 2013:270.

Blika P., Stamatelatou K., Kornaros M. and Lyberatos G. (2009) Anaerobic digestion of Olive Mill Wastewater. Global NEST Journal, 11:364-372. https://doi.org/10.30955/gnj.000605 stronger and lasting. Incentives for the operation of the olive growers could be the benefits which will result from the operation of the unit. If it is supposed that a typical energy consumption with an oil mill is close to $11-12 \mathrm{~kW}$, then the total energy consumption of the 33 oil mills operating will be about 3.3 MW and thus a large part of the unit's electricity produced could be available for the needs of olive oil mills.

What is more, there should be a citizens' information campaign presenting the benefits of this investment. Particularly residents of the settlements from the areas as Temploni, Kanakades and Giannades could have immediate benefits from the operation of the unit. Apart from electricity, a district heating network could be created to benefit from the surplus of thermal energy. This solution, though ambitious and costly, would contribute to the qualitative upgrading of citizens lives and economic prosperity.

To summarize, the establishment of a heat and power generation facility through anaerobic digestion of oil mill waste in the peripheral unit of Corfu has the potential to upgrade the island of Corfu regarding energy production and at the same time effectively tackle the chronic problem which has arisen from olive oil waste. However, this is characterized by many difficulties and obstacles. The most important of them is: a) the achievement of a steady flow of waste to the plant, $b$ ) the reluctance of the mills to dispose of the oil mill for anaerobic digestion, c) the citizens' reactions to the establishment of the unit and d) finding a suitable location for the installation. It is worth mentioning that, for the above reasons, many efforts have not been successful since the last few years, by various institutions (an association of oil mills, municipal authorities), for the creation of these centralized waste management units.

Dounavis A.S., Ntaikou I. and Lyberatos G. (2015) Production of biohydrogen from crude glycerol in an upflow column bioreactor, Bioresource Technology, 198:701-708. https://doi. org/10.1016/j.biortech.2015.09.072

Dounavis A.S., Ntaikou I., Kamilari M. and Lyberatos,G. (2016) Production of advanced biobased hydrogen enriched methane from waste glycerol in a two stage continuous system, Waste and Biomass Valorization, 7:677-689. https://doi.org/10.1007/ s12649-016-9538-9 
Eunomia Research \& Consulting Ltd. (2009) Assessment of the options to improve the management of bio-waste in the European Union. Annex E: Approach to estimating costs. European Commission.

Fabien M. (2003) An Introduction to the Anaerobic Digestion of Organic Waste. Remade Scotland.

Fountoulakis S., Dokianakis N., Kornaros M., Aggelis G. and Lyberatos G. (2002) Removal of phenolics in olive mill wastewaters using the white-rot fungus Pleurotus ostreatus. Water Research, 36:4735-4744. https://doi.org/10.1016/S00431354(02)00184-7

GSS (Greek Statistical Service), (2019) Retrieved from http:// www.statistics.gr .

Kalderis D. and Diamadopoulos E. (2010) Valorization of Solid Waste Residues from Olive Oil Mills: A Review. Terrestrial and Aquatic Environmental Toxicology, 4(1):7-20.

Hall E. (1992) Anaerobic Treatment of Wastewaters in Suspended Growth and Fixed Film Processes. In J. Malina, \& F. Pohland, Water Quality Management Library. Technomic Publishing Company.

Koutrouli E., Kalfas H., Gavala H., Skiadas I., Stamatelatou K. and Lyberatos G. (2009) Hydrogen and methane production through two-stage mesophilic anaerobic digestion of olive pulp. Bioresource Technology, 15(100):3718-3723. https://doi. org/10.1016/j.biortech.2009.01.037

Kavvadias V., Doula M., Komnitsas K. and Liakopoulou N. (2010) Disposal of Olive Oil Mill Wastes in Evaporation Ponds: Effects on Soil Properties. Journal of Hazardous Materials, 182:144-155. https://doi.org/10.1016/j.jhazmat.2010.06.007

Komnitsas K. and Zaharaki D. (2012) Pre-treatment of olive mill wastewaters at laboratory and mill scale and subsequent use in agriculture: Legislative framework and proposed soil quality indicators. Resources, Conservation \& Recycling, 69:82-89. https://doi.org/10.1016/j.resconrec.2012.09.009

La Cara F., lonata E., Del Monaco G., Marcolongo L., Gonçalves M. and Paula Marques I. (2012) Olive Mill Wastewater Anaerobically Digested: Phenolic Compounds with Antiradical Activity. Chemical Engineering Transactions, 12:325-330.

Loumou A. \& Giourga C. (2003) Olive Groves: The Life And Identity Of Mediterranean. Agriculture and Human Values, 20:87-95.https://doi.org/10.1023/A:1022444005336
Ministry of Environment and Energy (2019) «Environmental impact study for an electricity unit with fuel gas (biogas) and electric power $500 \mathrm{KWel»,} \mathrm{www.ypeka.gr}$

Montero I., Miranda T., Arranz J. and Rojas C. (2011) Thin Layer Drying Kinetics of By-Products from Olive Oil Processing. International Journal of Molecular Sciences, 12:7885-7897. https://doi.org/10.3390/ijms12117885

Morillo J. A., Antizar-Ladislao B., Monteoliva-Sanchez M., Ramos-Cormenzana A. and Russell N. (2009) Bioremediation and Biovalorisation of olive-mill wastes. Applied Microbiology and Biotechnology, 82:25-39.https://doi.org/10.1007/s00253008-1801-y

Ošlaj M. and Muršec B. (2010) Biogas as a renewable energy source. Tehnicki Vjesnik, 17(1):109-114.

Paraskeva P. and Diamadopoulos E. (2006) Technologies for Olive Mill Wastewater Treatment: A Review. Journal of Chemical Technology and Biotechnology, 81:1475-1485. https://doi. org/10.1002/jctb.1553

Rincón B., Fernando G. and Borja F. (2012) Olive Oil Mill Waste Treatment: Improving the Sustainability of the Olive Oil Industry with Anaerobic Digestion Technology. In D. Boskou, Olive Oil - Constituents, Quality, Health Properties and Bioconversions, 275-292. Retrieved from http://www.intechopen.com/books/ olive-oil-constituents-quality-health-properties-and bioconversions/anaerobic-treatment-of-olive-oil-mill-wastes-improving-the-sustainability-of-the-olive-oil industry. https:// doi.org/10.5772/28583

Samer M. (2012) Biogas Plant Constructions. In S. Kumar, Biogas, 343-368. Retrieved from http://www.intechopen. com/books/biogas/biogas-plant-constructions. https://doi. org/10.5772/31887

Stamatakis G. (2010) Energy and geo-environmental applications for Olive Mill Wastes: A review. Hellenic Journal of Geosciences, 45:269-282.

Sutton P. (1990) Anaerobic Treatment of High Strength Wastes: System Configurations and Selection. Milwaukee: University of Winsconcin.

Valta K., Aggeli E., Papadaskalopoulou C., Panaretou V., Sotiropoulos A., Malamis D. and Haralambous K.-J. (2015) Adding Value to Olive Oil Production Through Waste and Wastewater Treatment and Valorisation: The Case of Greece. Waste and Biomass Valorization, 6(5):913-925.https://doi.org/10.1007/ s12649-015-9373-4 